\title{
A coding polymorphism in matrix metalloproteinase 9 reduces risk of scarring sequelae of ocular Chlamydia trachomatis infection
} Angels Natividad*1,2, Graham Cooke ${ }^{2}$, Martin J Holland ${ }^{1,3}$,

\author{
Matthew J Burton ${ }^{1}$, Hassan M Joof ${ }^{3}$, Kirk Rockett ${ }^{2}$, Dominic P Kwiatkowski², \\ David CW Mabey ${ }^{1}$ and Robin L Bailey ${ }^{1}$
}

\author{
Address: ${ }^{1}$ London School of Hygiene \& Tropical Medicine, London University, London, UK, ${ }^{2}$ Wellcome Trust Centre for Human Genetics, \\ University of Oxford, Oxford, UK and ${ }^{3}$ Medical Research Council Laboratories, Fajara, The Gambia \\ Email: Angels Natividad* - angels.natividad-sancho@lshtm.ac.uk; Graham Cooke - grahamscooke@hotmail.com; \\ Martin J Holland - mholland@mrc.gm; Matthew J Burton - matthew.burton@lshtm.ac.uk; Hassan M Joof - hmjoof@yahoo.co.uk; \\ Kirk Rockett - Kirk.rockett@well.ox.ac.uk; Dominic P Kwiatkowski - dominic.kwiatkowski@paediatrics.ox.ac.uk; \\ David CW Mabey - david.mabey@lshtm.ac.uk; Robin L Bailey - robin.bailey@lshtm.ac.uk \\ * Corresponding author
}

Published: 27 April 2006

BMC Medical Genetics 2006, 7:40 doi: 10.1 I86/147|-2350-7-40

This article is available from: http://www.biomedcentral.com//47/-2350/7/40

(c) 2006 Natividad et al; licensee BioMed Central Ltd.

This is an Open Access article distributed under the terms of the Creative Commons Attribution License (http://creativecommons.org/licenses/by/2.0), which permits unrestricted use, distribution, and reproduction in any medium, provided the original work is properly cited.
Received: 13 February 2006

Accepted: 27 April 2006

\begin{abstract}
Background: Trachoma, an infectious disease of the conjunctiva caused by Chlamydia trachomatis, is an important global cause of blindness. A dysregulated extracellular matrix (ECM) proteolysis during the processes of tissue repair following infection and inflammation are thought to play a key role in the development of fibrotic sequelae of infection, which ultimately leads to blindness. Expression and activity of matrix metalloproteinase 9 (MMP-9), a major effector of ECM turnover, is up-regulated in the inflamed conjunctiva of trachoma subjects. Genetic variation within the MMP9 gene affects in vitro MMP9 expression levels, enzymatic activity and susceptibility to various inflammatory and fibrotic conditions.
\end{abstract}

Methods: We genotyped 65I case-control pairs from trachoma endemic villages in The Gambia for coding single nucleotide polymorphisms (SNPs) in the MMP9 gene using the high-throughput Sequenom ${ }^{\circledR}$ system. Single marker and haplotype conditional logistic regression (CLR) analysis for disease association was performed.

Results: The Q279R mutation located in exon 6 of MMP9 was found to be associated with lower risk for severe disease sequelae of ocular Chlamydia trachomatis infection. This mutation, which leads to a nonsynonymous amino-acid change within the active site of the enzyme may reduce MMP-9-induced degradation of the structural components of the ECM during inflammatory episodes in trachoma and its associated fibrosis.

Conclusion: This work supports the hypothesis that MMP-9 has a role in the pathogenesis of blinding trachoma.

\section{Background}

Trachoma, a chronic keratoconjunctivitis caused by
Chlamydia trachomatis, is the commonest infectious cause of blindness. The blinding complications of trachoma are 
due to progressive scarring of the conjunctiva (trachomatous scarring) eventually leading to in-turning of eyelashes (trichiasis) and corneal opacification. Genital C. trachomatis infection causes similar lesions in the female genital tract contributing to ectopic pregnancy and infertility. Severe and persistent inflammation triggered by repeated conjunctival infections is believed to increase the risk of pathological scarring later in life[1].

The mechanisms of disease pathology are not completely understood. Some evidence suggests that the dysregulated ECM proteolysis seen during the processes of tissue repair following infection and inflammation [2] may play a key role in the development of fibrotic sequelae of chlamydial infection in humans. In support of this hypothesis, we have recently shown that ocular $C$. trachomatis infection upregulates the expression of MMP-9 in the human conjunctival epithelium [3]. MMP-9 activity has been detected in immune cells present in the inflammatory infiltrate in conjunctival biopsy specimens from individuals with active trachoma [4]. In addition recent comparative studies of the role of MMP-9 in genital Chlamydia muridarum (MoPn) infection found greater MMP-9 transcription and activity during infection in those mouse strains exhibiting increased susceptibility to fibrotic sequelae following infection $[5,6]$.

Matrix metalloproteinases (MMPs) are a tightly regulated family of zinc-dependent enzymes that degrade structural proteins of the ECM and basement membranes. Among them, MMP-9 is a major effector of ECM turnover during homeostasis and pathology [7]. MMP9 expression is regulated at the transcriptional level in response to proinflammatory cytokines such as tumor necrosis factor (TNF) and interleukin 1 beta (IL-1 $\beta$ ) [8]. Post-transcriptional regulation also occurs by control of activation of the secreted pro-enzyme (proMMP-9), and inhibition of proMMP-9 and MMP-9 by tissue inhibitors (TIMPs) [7].

A number of SNPs have been identified in regulatory and coding regions of the MMP9 gene. Some of them have been reported to affect in vitro MMP9 expression levels, enzymatic activity and susceptibility to various inflammatory and fibrotic conditions [9]. We tested the hypothesis that genetic variation in coding regions of MMP9 affects the risk of scarring sequelae of trachoma.

\section{Methods}

Patients

One thousand three hundred and fifteen subjects identified by clinical examination using World Health Organization (WHO) criteria were recruited from trachoma endemic villages in The Gambia. They included 651 subjects with scarring trachoma (TS), of whom 307 additionally had trichiasis (TT), and pair-matched by sex, age, ethnic group and village of residence individuals with normal eyelids. The subjects were otherwise healthy. We have previously studied and reported polymorphism at the IFN $\gamma$ and IL10 loci in these subjects [10]. The study and its procedures were approved by the Gambia Government/MRC Ethics Committee (SCC 729/857), the Ethics committees of the London School of Hygiene and Tropical Medicine and of Oxford University, and are in accordance with the Declaration of Helsinki. Subjects diagnosed with trichiasis were offered free corrective surgery.

\section{DNA extraction and SNP genotyping}

Genomic DNA was isolated from either venous blood in EDTA or buccal brush samples and genotypes were determined by the Sequenom ${ }^{\circledR}$ system as previously described [10]. Primer sequences are available on request.

\section{Analytical methods}

Haplotype reconstruction and frequencies

Haplotypes were inferred from population genotype data and their frequencies were estimated as previously described [10].

\section{Association analysis}

A crude analysis (crude Mantel-Haenzsel) was first carried out using chi-square testing to test for differences in allele and haplotype frequencies between cases of TS and TT with their pair-matched controls. In addition, conditional logistic regression (CLR) analysis for disease association was performed. Conditional logistic regression is the analysis of choice for dichotomous paired data (in our case paired cases and controls) where the risk estimates associated with specific attributes (e.g genotype) are required to be adjusted for potential confounders. Reference genotypes were selected to be those that were common in our study population. A CLR test for trend in the odds ratios (OR) was performed to examine dose response effects in the relationship between genotype and disease. All analyses were performed using STATA (v8.0) software.

\section{Results \\ Single-marker analysis}

A total of four exonic SNPs of population frequency > $10 \%$ were typed at the MMP9 locus (Figure 1). The distribution of all marker genotypes among cases and controls were in Hardy-Weinberg equilibrium (data not shown). Table 1 shows the genotype frequencies at each locus for each phenotype and the results of CLR association analysis of matched case-control pairs. The Q279R G allele frequency was marginally higher among controls than scarred subjects $(0.31$ vs $0.27, \mathrm{OR}=0.854,95 \% \mathrm{CI}=$ $0.714,1.021, \mathrm{p}=0.083)$. The Q279R G allele was present in $45.1 \%$ of TS subjects against $51.6 \%$ of controls, and in $38.7 \%$ of TT subjects compared to $52.0 \%$ of controls. In adjusted analysis, presence of the Q279R G allele was 


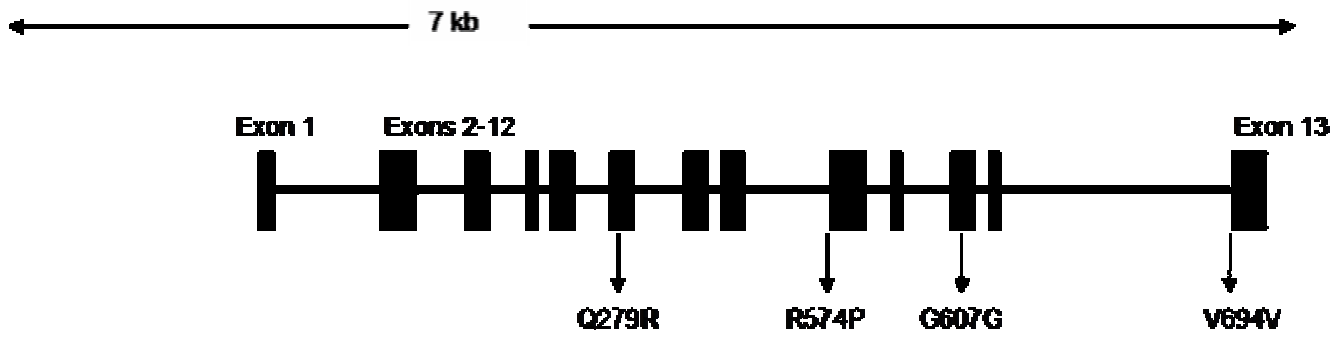

\begin{tabular}{lcccccc}
$\begin{array}{c}\text { dbSNP } \\
\text { reference }^{\mathrm{a}}\end{array}$ & $\begin{array}{c}\text { Chromosomal } \\
\text { coordinate }^{\mathrm{b}}\end{array}$ & $\begin{array}{c}\text { Amino acid } \\
\text { position }\end{array}$ & Alleles & Function & \multicolumn{2}{c}{$\begin{array}{c}\text { Frequency } \\
\text { scarred } \\
\text { cases }\end{array}$} \\
\hline rs2664538 & 44073632 & Q279R (exon 6) & $\mathrm{A} \rightarrow \mathrm{G}$ & nonsynonymous change & 0.27 & 0.31 \\
rs2250889 & 44075813 & $\mathrm{R} 574 \mathrm{P}($ exon 10) & $\mathrm{G} \rightarrow \mathrm{G}$ & nonsynonymous change & 0.15 & 0.15 \\
rs13969 & 44076240 & $\mathrm{G} 607 \mathrm{G}$ (exon 11) & $\mathrm{A} \rightarrow \mathrm{C}$ & synonymous change & 0.42 & 0.41 \\
rs13925 & 44078372 & $\mathrm{~V} 694 \mathrm{~V}$ (exon 13) & $\mathrm{G} \rightarrow \mathrm{A}$ & synonymous change & 0.14 & 0.14
\end{tabular}

Note: ${ }^{a}$ http://www.ncbi.nlm.nih.gov/projects/SNP/, ${ }^{\mathrm{b}}$ coordinate in chromosome 20q11.213.1 as described in Ensemble release v34. Oct 2005

Figure I

Diagram showing genotyped SNPs labelled according to the amino acid position.

associated with a reduced risk of $\mathrm{TS}(\mathrm{OR}=0.74,95 \% \mathrm{CI}=$ $0.59,0.94, \mathrm{p}=0.012)$, and with a greater decrease in risk for the more severe $\mathrm{TT}$ phenotype $(\mathrm{OR}=0.66,95 \% \mathrm{CI}=$ $0.46,0.94, \mathrm{p}=0.021)$. Although there was some evidence for a trend towards decreasing risk of TS and TT with increasing number of Q279R G alleles, it did not reach statistical significance $(\mathrm{OR}=0.864,95 \% \mathrm{CI}=0.727,1.027$ and $\mathrm{OR}=0.832,95 \% \mathrm{CI}=0.644,1.074$ for $\mathrm{TS}$ and $\mathrm{TT}$ respectively). Heterozygotes Q279R AG were at lower risk of both TS and TT $(\mathrm{OR}=0.69,95 \% \mathrm{CI}=0.54,0.81, \mathrm{p}=$ 0.004 and $\mathrm{OR}=0.57,95 \% \mathrm{CI}=0.38,0.85 \mathrm{p}=0.006$ respectively) (data in Table 1).

\section{Haplotype analysis}

Table 2 shows the estimated frequency and associated risks of TS and TT by multivariate CLR analysis for inferred haplotypes at the MMP9 locus spanning exons 6 to 13 . The 4 SNP sites segregated into seven haplotypes. Four common haplotypes with population frequency $>10 \%$ accounted for more than $80 \%$ of total variation, suggesting high linkage disequilibrium (LD) between segregating sites.
The GCAG haplotype was associated with lower risk of TS and TT (Table 2). The risk of both TS and TT decreased with the number of copies of the haplotype GCAG (test for trend $\mathrm{OR}=0.81,95 \% \mathrm{CI}=0.63,1.02, \mathrm{p}=0.07$ and $\mathrm{OR}$ $=0.6795 \% \mathrm{CI}=0.46,0.96, \mathrm{p}=0.03$ for TS and TT respectively). The GCAG-haplotype effect on risk of TT was greater than that on risk of TS.

Haplotypes containing the Q279R G allele, itself associated with decreased risk, were more commonly seen among controls than cases, although the difference in haplotype frequency between cases and controls reach significance only for haplotype GCAG. Conversely, the commonest haplotypes ACCG and ACAG were more frequently seen among cases than controls, and both carry the Q279R A allele. The strength of the single marker association is very similar to, if not greater than that of the haplotype, which supports the suggestion that the Q279R SNP itself may be causal.

\section{Discussion}

The present study found a coding SNP (Q279R in exon 6) within the MMP9 gene to be associated with a lowered risk of trachomatous scarring and trichiasis, which was 
Table I: Genotype frequencies for the polymorphisms at the MMP9 locus in the study population and risk estimates from CLR analysis of matched case-control pairs.

\begin{tabular}{|c|c|c|c|c|c|}
\hline \multicolumn{6}{|c|}{ Polymorphisms at the MMP9 locus in the study population } \\
\hline \multirow[t]{2}{*}{ Genotype } & \multicolumn{2}{|c|}{ \# of genotype (freq) } & \multirow{2}{*}{$\begin{array}{l}\text { crude } \mathrm{M}-\mathrm{H} \\
\text { OR( }(95 \% \mathrm{Cl})\end{array}$} & \multirow[t]{2}{*}{ CLR-OR $(95 \% \mathrm{Cl})$} & \multirow[t]{2}{*}{$P$ value } \\
\hline & Scarring cases (TS) & controls & & & \\
\hline Q279R AA & $330(0.55)$ & $311(0.48)$ & $1.18(1.00,1.38)$ & reference & - \\
\hline Q279R AG & $209(0.35)$ & $270(0.42)$ & $0.80(0.67,0.96)$ & $0.70(0.54,0.89)$ & 0.004 \\
\hline Q279R GG & $62(0.10)$ & $61(0.10)$ & $1.07(0.74,1.55)$ & $0.95(0.64,1.41)$ & 0.805 \\
\hline R574P CC & $450(0.73)$ & $459(0.72)$ & $0.98(0.86,1.12)$ & reference & - \\
\hline R574P CG & $155(0.25)$ & $161(0.25)$ & $0.96(0.77,1.20)$ & $0.97(0.74,1.28)$ & 0.845 \\
\hline R574P GG & $15(0.02)$ & I4(0.02) & $1.07(0.52,2.22)$ & $1.07(0.50,2.28)$ & 0.857 \\
\hline G607G AA & $204(0.35)$ & $193(0.35)$ & $1.06(0.87,1.29)$ & reference & - \\
\hline G607G AC & $265(0.46)$ & $268(0.48)$ & $0.99(0.83,1.17)$ & $0.91(0.68,1.22)$ & 0.538 \\
\hline G607G CC & $114(0.20)$ & $94(0.17)$ & $1.21(0.92,1.59)$ & $1.06(0.73,1.55)$ & 0.746 \\
\hline V694V GA & $453(0.75)$ & $443(0.74)$ & $1.02(0.90,1.17)$ & reference & - \\
\hline V694V GG & $138(0.23)$ & $145(0.24)$ & $0.95(0.75,1.20)$ & $0.94(0.71,1.26)$ & 0.694 \\
\hline V694V AA & $14(0.02)$ & $\mathrm{II}(0.02)$ & $1.27(0.58,2.80)$ & I.II $(0.49,2.48)$ & 0.807 \\
\hline
\end{tabular}

Risk estimates from CLR analysis of matched case-control pairs

\begin{tabular}{|c|c|c|c|c|c|}
\hline Q279R AA & $166(0.61)$ & $131(0.48)$ & 1.28 (1.01, I.59) & reference & - \\
\hline Q279R AG & $75(0.28)$ & $\mathrm{II}(0.43)$ & $0.64(0.48,0.86)$ & $0.57(0.38,0.85)$ & 0.006 \\
\hline Q279R GG & $30(0.11)$ & $25(0.11)$ & $1.20(0.71,2.04)$ & $0.95(0.54,1.69)$ & 0.945 \\
\hline R574P CC & $218(0.74)$ & $213(0.71)$ & $1.02(0.85,1.24)$ & reference & - \\
\hline R574P CG & $68(0.23)$ & $80(0.27)$ & $0.85(0.62,1.17)$ & $0.76(0.50,1.14)$ & 0.181 \\
\hline R574P GG & $7(0.02)$ & $7(0.02)$ & $1.00(0.35,2.85)$ & $1.06(0.3 I-3.69)$ & 0.927 \\
\hline G607G AA & $97(0.35)$ & $101(0.37)$ & $0.96(0.73,1.27)$ & reference & - \\
\hline G607G AC & $127(0.46)$ & $132(0.48)$ & $0.96(0.75,1.23)$ & $0.96(0.63,1.46)$ & 0.851 \\
\hline G607G CC & $55(0.20)$ & $43(0.16)$ & $1.28(0.86,1.91)$ & $1.03(0.60,1.78)$ & 0.908 \\
\hline V694V GA & $225(0.79)$ & $213(0.76)$ & $1.06(0.88,1.27)$ & reference & - \\
\hline V694V GG & $54(0.19)$ & $63(0.22)$ & $0.86(0.60,1.23)$ & $0.94(0.60,1.48)$ & 0.371 \\
\hline V694V AA & $5(0.02)$ & $5(0.02)$ & $1.00(0.29,3.45)$ & $0.79(0.21,2.95)$ & 0.725 \\
\hline
\end{tabular}

more marked for trichiasis. This supports the validity of the association because trichiasis is a more advanced form of cicatricial trachoma and also less subject to clinical misclassification than scarring trachoma.

The Q279R mutation leads to the substitution of a positively charged amino-acid (arginine) by an uncharged amino acid (glutamine) at position 279 within the MMP9 active site. Although the functional impact of this poly- morphism on the protein is unknown, this variant is noteworthy; it is located in the coding sequence of one of the highly conserved fibronectin type II-like repeats which confers MMP-9 with high affinity binding to type IV collagen, type I gelatin and elastin $[11,12]$. The digestion of type IV collagen in the epithelial basement membrane has been suggested to be a key regulatory event in the initiation of fibrosis. A plausible explanation of these results is that Q279R represents a partial loss-of-function mutation 
Table 2: Comparison of MMP9 haplotype frequency estimates in cases and controls and risk estimates from CLR analysis of matched case-control pairs. The haplotype configuration is as follows: Q279R, R574P, G607G and V694V.

\begin{tabular}{ccccccccccccc}
\hline haplotype & \# controls & freq & \# cases (TS) & freq & p-value & CLR:OR $(95 \% C l)$ & \# controls & freq & \# cases(TT) & freq & P-value & CLR:OR (95\%Cl) \\
\hline ACCG & 450 & 0.34 & 466 & 0.36 & - & reference & 204 & 0.32 & 218 & 0.36 & - & reference \\
ACAG & 298 & 0.22 & 303 & 0.23 & 0.845 & $0.98(0.80,1.21)$ & 150 & 0.24 & 167 & 0.27 & 0.514 & $1.11(0.82,1.50)$ \\
GCAA & 201 & 0.15 & 186 & 0.14 & 0.257 & $0.87(0.69,1.11)$ & 91 & 0.14 & 75 & 0.12 & 0.224 & $0.79(0.54,1.15)$ \\
GCAG & 161 & 0.12 & 130 & 0.10 & 0.048 & $0.77(0.59,0.99)$ & 80 & 0.13 & 55 & 0.09 & 0.021 & $0.62(0.41,0.93)$ \\
AGAG & 123 & 0.09 & 130 & 0.10 & 0.705 & $1.06(0.79,1.40)$ & 61 & 0.10 & 55 & 0.09 & 0.451 & $0.85(0.56,1.30)$ \\
AGCG & 66 & 0.05 & 55 & 0.04 & 0.204 & $0.78(0.53,1.15)$ & 33 & 0.05 & 27 & 0.04 & 0.171 & $0.66(0.37,1.20)$ \\
GCCG & 30 & 0.02 & 32 & 0.02 & 0.977 & $0.99(0.58,1.68)$ & 13 & 0.02 & 17 & 0.03 & 0.604 & $1.24(0.56,2.75)$
\end{tabular}

within the proteinase whose presence reduces the development of fibrosis; these findings implicate MMP-9 as a key molecule in the pathogenesis of conjunctival scarring in trachoma.

The effect observed in this work was primarily associated with the Q279R GA heterozygous genotype. It is possible that the apparent lack of statistical effect of the GG homozygous genotype may have resulted from the modest sample size within the Q279R GG stratum. However we do not rule out the possibility of this finding being genuine and of biological significance; the increased risk of cicatricial trachoma associated with the Q279R AA homozygous genotype may be linked to the excessive MMP-9-driven proteolytic activation seen in the chronic inflammatory environment of the conjunctiva of subjects with trachoma[3,4]. Conversely, if Q279R GG homozygotes secrete only "sub-functional" copies of the enzyme, associated with low MMP-9 activity, this may result in disordered tissue remodelling because of a greater deposition of matrix, which has been found to correlate with hypertrophic scars[13]. In this setting, an advantage for Q279R GA heterozygotes could arise from the secretion of both native and defective forms of the enzyme at the site of inflammation upon cellular activation. This may lead to both a reduction of tissue proteolysis in chronic inflammation and protection against excessive tissue destruction and scarring.

MMP-9 expression and activity is up-regulated in the inflamed conjunctiva of trachoma subjects and increases with the severity of clinical inflammation $[3,4]$. There is evidence to suggest that the elevated local levels of TNF and IL-1 $\beta$ associated with chlamydial infection and inflammation[3] act as an important trigger of matrix degradation by inducing MMP-9 activity in inflamed tissue. Destruction of the ECM may facilitate cell migration and result in the characteristic infiltrating leukocytes and stromal cells (e.g. macrophages and fibroblasts) seen in trachoma subjects[4]. The secretion of MMP-9, cytokines and chemokines by these cells may drive the inflammatory process into a positive feedback loop. MMP-9 can activate pro-inflammatory cytokines[14] which may fur- ther increase and perpetuate inflammation leading to persistent tissue damage. Later during the tissue repair phase, excessive MMP activities may contribute to contractile scarring, characteristic of TS and TT, through their role in ocular fibroblast-mediated matrix contraction $[15,16]$. It is plausible that persistently increased MMP9 activity in the conjunctiva of subjects with trachoma may be a key event in the pathogenesis of conjunctival scarring through excessive degradation of ECM and fibrosis. The recent characterisation of MMP-9 expression and activity in mouse strains exhibiting variable susceptibility to sequelae of genital Chlamydia muridarum (MoPn) infection[5] supports this suggestion: $\mathrm{C} 3 \mathrm{H} / \mathrm{HeN}$ mice, which are particularly susceptible to fibrotic sequelae in this model[6], exhibited greater MMP-9 transcription and activity during infection.

The blinding lesion in trachoma is corneal opacity (CO), which is thought to result from the lashes rubbing against the eyeball (TT) and damaging the cornea. Epidemiological studies indicate that after successful TT surgery, CO can develop[17], and there is evidence that inflammatory episodes in TT subjects correlate with the presence of $\mathrm{CO}$ [15]. MMPs are expressed at sites of epithelial loss in ulcerated corneas and found in the tear film of patients with external ocular inflammatory disorders[18]. In the cornea, an imbalance in MMP9 production has been implicated in corneal scarring and loss of corneal transparency and visual function[7]. Proteolytic destruction of the glandular tissue contributes to reduced secretion of tears, and is associated with a number of corneal pathologies[7]. The constant exposure of the corneal surface to conjunctival and/or tear MMP-9 and inflammatory cytokines may contribute to progressive corneal opacification. CO may be a relevant phenotype for MMP9 genetic association analysis, but for practical reasons large numbers of patients with $\mathrm{CO}$ are difficult to come by.

\section{Conclusion}

This work supports the hypothesis that MMP-9 has a role in the pathogenesis of blinding trachoma. The risk reductions associated with the Q279R exonic mutation are modest: $26 \%$ for scarring and $34 \%$ for trichiasis. CLR 
analysis suggests that these effects are independent of those previously reported in the interleukin 10 (IL10) and interferon gamma $(I F N \gamma)$ loci [10]. This is consistent with a model of cicatricial trachoma as a complex disorder with multiple genetic factors contributing to risk of scarring and trichiasis after ocular chlamydial infection. Further studies of MMP-9 in chlamydial infection and of the functional significance of genetic variation at the MMP-9 locus, are warranted.

\section{Abbreviations}

ECM -extracellular matrix, MMP -matrix metalloproteinase, SNP -single nucleotide polymorphisms, CLR -conditional logistic regression, TIMPs - tissue inhibitors of matrix metalloproteinases, WHO -World Health Organization, TS -scarring trachoma, TT -trichiasis, OR -odds ratio, CI -confidence interval, LD- linkage disequilibrium, $\mathrm{CO}$-corneal opacity, TNF -tumor necrosis factor, IL- $1 \beta$ interleukin 1 beta, IL10 -interleukin 10, IFN $\gamma$-interferon gamma.

\section{Competing interests}

The author(s) declare that they have no competing interests.

\section{Authors' contributions}

AN collected, edited, analysed the data and wrote the manuscript. RB directed the study, study design and cowrote the manuscript. GC study design and contributed to the manuscript. $\mathrm{DM}, \mathrm{MH}$ and $\mathrm{MB}$ directed the study, study design and contributed to the manuscript. DK and KR co-directed the study. OJ and $\mathrm{HJ}$ collected clinical data and provide clinical material

\section{Acknowledgements}

We thank the study participants, field workers and laboratory staff at the Medical Research Council Laboratories in The Gambia for their assistance. This work was supported by the Medical Research Council (UK).

\section{References}

I. Mabey DCW, Hutin YJF, Bailey RL: The epidemiology and pathogenesis of trachoma. Rev Med Microbiol 1992, 3: I I2-119.

2. Abu el-Asrar AM, Geboes K, Missotten L: Immunology of trachomatous conjunctivitis. Bull Soc Belge Ophtalmol 2001:73-96.

3. Burton, Bailey RLM, Jeffries D, Mabey DC, Holland MJ: Cytokine and fibrogenic gene expression in the conjunctivas of subjects from a Gambian community where trachoma is endemic. Infect Immun 2004, 72(I 2):7352-7356.

4. EL-Asrar AM, Geboes K, Al-Kharashi SA, Al-Mosallam A, Missotten L, Paemen L, Opdenakker G: Expression of gelatinase B in trachomatous conjunctivitis. Br J Ophthalmol 2000, 84:85-9I.

5. Ramsey KHIM, Sigar JH, Schripsema Shaba N, Cohoon KP: Expression of matrix metalloproteinases subsequent to urogenital Chlamydia muridarum infection of mice. Infect Immun 2005, 73(I 0):6962-73.

6. Shah AA, Schripsema JH, Imtiaz MT, Sigar IM, Kasimos J, Matos PG, Inouye S, Ramsey $\mathrm{KH}$ : Histopathologic changes related to fibrotic oviduct occlusion after genital tract infection of mice with Chlamydia muridarum. Sex Transm Dis 2005, 32:49-56.

7. Wong T, Sethi TC, Daniels JT, Limb GA, Murphy G, Khaw PT: Matrix metalloproteinases in disease and repair processes in the anterior segment. Surv Ophthalmol 2002, 47(3):239-56.
8. Saren P, Welgus HG, Kovanen PT: TNF-alpha and IL-I beta selectively induce expression of 92-kDa gelatinase by human macrophages. J Immunol 1996, I 57(9):4159-65.

9. Zhang $B$, Ye S, Herrmann SM, Eriksson $P$, de Maat M, Evans $A$ Arveiler D, Luc G, Cambien F, Hamsten A, Watkins H, Henney AM: Functional polymorphism in the regulatory region of gelatinase $B$ gene in relation to severity of coronary atherosclerosis. Circulation 1999, 99: I788-1794.

10. Natividad A, Wilson J, Kock O, Holland MJ, Rockett K, Faal N, Jallow O, Joof HM, Burton MJ, Alexander ND, Kwiatkowski DP, Mabey DC, Bailey RL: Risk of trachomatous scarring and trichiasis in Gambians varies with SNP-haplotypes at the interferongamma and interleukin-IO loci. Genes and Immun 2005, 6:332-340.

II. Collier IE, Krasnov PA, Strongin AY, Birkedal-Hansen H, Goldberg GI: Alanine scanning mutagenesis and functional analysis of the fibronectin-like collagen-binding domain from human 92kDa type IV collagenase. J Biol Chem I992, 267( I 0):6776-8I.

12. Shipley JM, Doyle GA, Fliszar CJ, Ye QZ, Johnson LL, Shapiro SD, Welgus HG, Senior RM: The structural basis for the elastolytic activity of the $92-\mathrm{kDa}$ and 72-kDa gelatinases. Role of the fibronectin type Il-like repeats. J Biol Chem 1996, 27 I (8):4335-4I.

13. Neely AN, Clendening CE, Gardner J, Greenhalgh DG, Warden GD: Gelatinase activity in keloids and hypertrophic scars. Wound Repair Regen 1999, 7(3): I66-7I.

14. Gearing A, Beckett P, Christodoulou M, Churchill M, Clements JM, Crimmin M, Davidson AH, Drummond AH, Galloway WA, Gilbert R: Matrix metalloproteinases and processing of TNFa. J Leukoc Biol 1995, 57:774-777.

15. Daniels JT, Cambrey AD, Occleston NL, Garrett Q, Tarnuzzer RW, Schultz GS, Khaw PT: Matrix metalloproteinase inhibition modulates fibroblast-mediated matrix contraction and collagen production in vitro. Invest Ophthalmol Vis Sci 2003, 44(3): I 104- 10.

16. Wong TT, Mead AL, Khaw PT: Matrix metalloproteinase inhibition modulates postoperative scarring after experimental glaucoma filtration surgery. Invest Ophthalmol Vis Sci 2003, 44(3): 1097-103.

17. Burton MJ, Kinteh F, Jallow O, Sillah A, Bah M, Faye M, Aryee EA, Ikumapayi UN, Alexander ND, Adegbola RA, Faal H, Mabey DC, Foster $A$, Johnson GJ, Bailey RL: A randomised controlled trial of azithromycin following surgery for trachomatous trichiasis in The Gambia. Br J Ophthalmol 2005, 89: I 282-I 288.

18. Leonardi A, Brun P, Abatangelo G, Plebani M, Secchi AG: Tear levels and activity of matrix metalloproteinase (MMP)- I and MMP9 in vernal keratoconjunctivitis. Invest Ophthalmol Vis Sci 2003, 44(7):3052-8.

\section{Pre-publication history}

The pre-publication history for this paper can be accessed here:

http://www.biomedcentral.com/1471-2350/7/40/prepub

Publish with Biomed Central and every scientist can read your work free of charge

"BioMed Central will be the most significant development for disseminating the results of biomedical research in our lifetime. "

Sir Paul Nurse, Cancer Research UK

Your research papers will be:

- available free of charge to the entire biomedical community

- peer reviewed and published immediately upon acceptance

- cited in PubMed and archived on PubMed Central

- yours - you keep the copyright
BioMedcentral 